\title{
Uma leitura de Os paraísos artificiais, de Charles Baudelaire, sob a ótica da psicofarmacologia
}

\author{
A reading of Artificial paradises, by \\ Charles Baudelaire, from the perspective of \\ psychopharmacology
}

\author{
Josillene PINHeIRO-Mariz \\ SAULO RIOS MARIZ*
}

Resumo: Este trabalho objetiva analisar, sob a ótica da psicofarmacologia, a perspectiva baudelairiana do estágio biopsicossocial alcançado com o uso de drogas. Para tanto, apresenta-se uma leitura de Os paraísos artificiais. Enfoca-se a necessidade humana de uma eterna busca por um prazer obtido somente nesse estado de transcendência, segundo o poeta. Assim, Baudelaire discorre sobre os tais paraísos artificiais, químicos ou não, argumentando que eles são necessários para a criação poética e, sobretudo, para estimular o imaginário. Conclui-se com reflexões sobre a leitura de textos literários como estratégia para a prevenção ao uso indevido de drogas e à farmacodependência.

Palavras-chave: paraísos artificiais, drogas psicoativas, Charles Baudelaire

\begin{abstract}
This paper aims to examine, with a psychopharmacology approach, the Charles Baudelaire's perspective about the biopsychosocial stage reached with the use of drugs. Therefore, it presents a reading of Artificial paradises. We focus on the human need for an eternal search for a pleasure obtained only in this state of transcendence, according to the poet. Thus, Baudelaire talks about these artificial paradises, chemicals or not, stating that they are necessary for poetic creation and, above all, to stimulate the imagination. We conclude with reflections about the reading of literary texts as a strategy for the prevention on drug abuse and pharmacodependence.
\end{abstract}

Keywords: artificial paradises, psychoactive drugs, Charles Baudelaire

Doutora e Mestre pela FFLCH (USP). Pós-doutora pela Université Paris 8. Professora da Graduação em Língua Francesa e Língua Portuguesa e do Programa de Pós-Graduação em Linguagem e Ensino (Mestrado), da Universidade Federal de Campina Grande.

** Mestre em Toxicologia (USP), Doutor em Farmacologia (UFPB) e Pós-Doutor pela Université Paris 8. Professor de Farmacologia e Toxicologia no Centro de Ciências Biológicas e da Saúde da Universidade Federal de Campina Grande. 


\section{Introdução}

A relação interdisciplinar entre as grandes áreas das Ciências da Linguagem e das Ciências Biológicas e da Saúde é rica, complexa e instigante. Inicialmente, devemos considerar que, por um lado, os pesquisadores e profissionais da biologia, da medicina e de outras áreas da saúde buscam desenvolver conhecimentos e transformá-los em ações concretas para melhoria contínua da qualidade da assistência em saúde, sendo que, para tanto, sempre lançaram mão de diversos tipos de linguagem não somente com fins de comunicação entre si e com os usuários dos seus serviços, mas também com a finalidade de registros diversos. Por outro lado, as linguagens são usadas pelo ser humano nas mais diversas áreas, viabilizando o seu desejo intrínseco de se expressar, de deixar registros de sua trajetória. A literatura, enquanto forma de expressão artística, brinca com as palavras percorrendo com destreza o tênue limiar entre a verossimilhança, que gera identificação no leitor, e a ficção que o encanta, cativando-o até a última página; fazendo-o experimentar diversas emoções como recompensa por ter aceitado o convite a visitar outros mundos - por vezes tão (ou mais) reais quanto o seu próprio.

Sabe-se que para a leitura analítica de um texto literário é fundamental considerar sua ancoragem sócio historiográfica para que elementos sutis sejam identificados e, posteriormente, investigados, sobretudo nas obras do século XIX, - em especial nas literaturas europeias -, pois esse período revela uma intensa transformação nas mais diversas áreas da sociedade; assim, portanto, a ancoragem historicista configura-se como fundamental para melhor se compreender a obra literária.

A literatura francesa dessa época, por exemplo, passou por intensas transformações, resultando em uma multifacetada produção literária, dando origem a diversas escolas e/ou estilos literários. Nesse período de pós Revolução, buscava-se um porto seguro, posto que, sem rei, o povo sofria de certa orfandade. Assim, os autores viram na escrita literária um caminho que traria solução para as eternas buscas. Entre eles, destacamos aqueles que podem ser considerados como os mais importantes da segunda metade do século XIX, os conhecidos como "malditos": Baudelaire, Verlaine, Rimbaud e Mallarmé. Eles influencia- 
ram não somente o seu tempo, mas dada a importância de sua obra, continuam como referência nos séculos posteriores.

A capacidade que tinha Baudelaire de instigar não somente a crítica como a própria sociedade da época com obras do quilate de Les fleurs du mal [As flores do mal] (1857) e Peintre de la vie moderne [O pintor da vida moderna] (1863) não parece ter sido tão ácida em Les Paradis Artificiels [Os Paraísos Artificiais] (1860), obra na qual se lê um detalhado ensaio sobre algumas drogas e os usos possíveis que delas são feitos, sendo este, portanto, o nosso foco nestas reflexões que buscam o elo entre a literatura e a medicina (BENJAMIN, 2015).

Em busca de melhor refletir sobre essa questão, perguntamo-nos qual o motivo de Paraísos Artificiais, mesmo relatando de modo detalhado os efeitos (inclusive os agradáveis) de três das mais usadas drogas psicoativas, não ter provocado a mesma reação de obras anteriores desse autor, como o recolho de poemas As flores do mal, que o levou aos tribunais? Será que, na época, ainda não haveria conhecimentos científicos suficientes sobre os efeitos prejudiciais das drogas dissertadas pelo poeta? Qual o motivo da tradicional sociedade francesa do século XIX não ter convulsionado com uma descrição tão pormenorizada das delícias psicodélicas apresentadas; descrição essa que poderia despertar curiosidades e desvirtuar toda uma geração? Acaso os detalhes de sensações descritas por Baudelaire em usuários de álcool, ópio e haxixe, condizem com as possibilidades de efeitos biológicos elencados pela neurociência moderna?

Assim, na tentativa de responder a essas indagações, debruçamo-nos sobre uma leitura que busca revelar outra face desse ensaio, na ótica da contemporaneidade e para tanto apoiamo-nos em especialistas no domínio das Ciências da Saúde (BRUNTON et al, 2007; DIEHL, FIGLIO, 2014; OGA et al, 2014; RONZANI et al, 2015) para a leitura do referido ensaio. Este trabalho, com base teórico-analítica, tem seus resultados ancorados nas reflexões baudelairianas e se dedica, essencialmente, a buscar verossimilhanças e ou elementos ficcionais na descrição sobre os efeitos psicoativos e a transcendência produzida pelos paraísos artificiais, de Charles Baudelaire. 


\section{Os paraísos artificiais, de Baudelaire}

Charles Baudelaire nasceu em 09 de abril de 1821, sempre teve uma vida dândi, financiada por uma família abastada que lhe propiciou viagens diversas, inclusive ao Oriente, em uma época em que essa região do mundo não era tão conhecida pelo Ocidente. Esse poeta e crítico faleceu em 31 de agosto de 1867, deixando uma vasta produção literária que influenciou todo o mundo ocidental literário, filosófico e artístico. Além disso, marcou a literatura francesa com a sua obra ora sarcástica, ora delicada e sutil (AMARAL, 1996).

Na obra em estudo, Os paraísos artificiais (1860), o autor discorre sobre três drogas: o haxixe, o vinho e ópio. Na primeira parte, o haxixe, um produto à base de maconha (Cannabis sativa L.), ele descreve seus efeitos euforizantes e sua capacidade de dilatar o tempo e exacerbar a sensibilidade. $\mathrm{O}$ tom discursivo não é elogioso, pois ressalta as propriedades negativas, entre as quais se podem destacar comportamentos como uma fadiga extrema e a preguiça. Os argumentos fundamentam-se nos relatos de outros usuários, bem como na sua própria experiência.

Que as pessoas da sociedade e os ignorantes, curiosos para conhecer os gozos excepcionais, saibam bem que não encontrarão no haxixe nada de miraculoso, absolutamente nada a não ser o natural excessivo.

Enquanto nós, poetas e filósofos, regeneramos nossa alma pelo trabalho excessivo e pela contemplação; pelo exercício assíduo da vontade e pela nobreza da intenção, criamos permanente para nosso uso, um jardim de beleza verdadeira (BAUDELAIRE, 2005, p. 23 e 28) ${ }^{1}$.

Convém destacar a informação do poeta de que o haxixe nada produz de miraculoso, apenas estimula o que já existe no homem natural, não fazendo nascer

1 Que les gens du monde et les ignorants, curieux de connaître des jouissances exceptionnelles, sachent donc bien qu'ils ne trouveront dans le haschisch rien de miraculeux, absolument rien que le naturel excessif.

[...] tandis que nous, poètes et philosophes, nous avons régénéré notre âme par le travail successif et la contemplation; par l'exercice assidu de la volonté et la noblesse permanente de l'intention, nous avons créé à notre usage un jardin de vraie beauté. (BAUDELAIRE, 2005, p. 10 e 38). Todas as traduções de Os Paraísos Artificiais são de José Saramago. 
criatividade e imaginação em quem não as têm. Ele faz uma diferenciação dos usuários em dois grandes grupos, como se fossem diferentes terrenos cujas características intrínsecas determinariam se uma semente plantada e adubada iria ou não germinar.

Ao discorrer sobre os efeitos do Ópio, Baudelaire apresenta a segunda parte do ensaio. A narrativa, assumidamente inspirada na obra do inglês Thomas de Quincey (Confissões de um comedor de ópio, 1822) é propositalmente um estímulo à confusão entre os relatos do comedor de ópio e as observações do poeta francês, gerando uma atmosfera relacionada aos efeitos hipnoanalgésicos que os alcaloides do ópio produzem nos cérebros a eles expostos (BRUNTON et al, 2007; OGA et al, 2014). Desse modo, o encontro com o texto parece se tornar quase tão imperativo quanto a droga para aquele que dela depende. Ao merguIhar no relato sobre os fatos da vida de Quincey, o leitor se depara com o prazer citado por Roland Barthes (2014), um prazer de dor e sofrimento. Esse entrelaçamento dos textos de Baudelaire e Quincey talvez decorra do fato de que essa segunda parte da obra é um grande palimpsesto de traduções e comentários. Ora, o autor foi um dos grandes tradutores, para o francês, de obras em inglês; tanto é que, com suas traduções, ajudou Edgar Allan Poe a ser reconhecido internacionalmente. A partir dos relatos de dramas pessoais do autor inglês, confusos e estetizantes, o francês apresenta as volúpias e torturas do ópio instigando as fragilidades humanas do leitor, levando-o aos mais diversos sentimentos.

A intencionalidade em tecer essa miscelânea, esse palimpsesto, parece-nos explicita.

"Que é o cérebro humano senão um palimpsesto imenso e natural? O meu cérebro é palimpsesto e o vosso também, leitor. Inúmeras camadas de ideias, de imagens, de sentimentos caíram sucessivamente sobre o vosso cérebro, tão suavemente como a luz. Cada um parecia sepultar a anterior. Mas, na realidade, nenhum apareceu". Todavia, entre o palimpsesto que apresenta, sobrepostas uma na outra, uma tragédia grega, uma lenda monástica e uma história de cavalaria, e o palimpsesto criado por Deus, que é a nossa incomensurável memória, há diferença de que no primeiro existe como que um caos fantástico, grotesco, uma colisão entre elementos heterogéneos, ao passo que no segundo a fatalidade do temperamento põe forçosamente uma harmonia entre elementos mais 
díspares. Por mais incoerente que seja uma existência, a unidade humana não é perturbadora." (BAUDELAIRE, 2005, p. 139, aspas do autor)².

Com um relato habilidoso de vivências, ideias e imagens que se superpõem em um labirinto infindo, como as camadas do tecido cerebral, o autor nos conduz a vivenciar as transcendências brilhantes, ou não, do seu amigo comedor de ópio. Observa-se, nesse excerto, o misto de narrativa "do comedor de ópio" e os comentários do poeta maldito que, ao mesmo tempo em que aparenta confusão, ele traz ao leitor uma conclusão que parece querer explicar que há harmonia no relato, da mesma forma que no cérebro, ainda que as camadas sobrepostas provoquem tal confusão. Afirmar que "Por mais incoerente que seja uma existência, a unidade humana não é perturbadora", pode-se entender que muito embora existam as camadas, dentro de sua confusão, o cérebro humano é intocável.

Na terceira parte da obra, Baudelaire retoma a ode ao vinho, já iniciada em As flores do mal (1857). Na comparação feita com as drogas anteriores, apresenta o vinho como elemento promotor de alegria e felicidade, tão necessárias à interação. Enquanto isso lembra que as outras drogas acompanham os solitários, entorpecem, deprimem e entristecem o ser humano.

\section{Uma leitura psicofarmacológica do vinho em Os paraísos artificiais}

Diferentemente do impacto negativo de As flores do mal, que foi repudiada socialmente, inclusive na esfera jurídica, o ensaio Os paraísos artificiais pare-

\footnotetext{
2 "Qu'est-ce que le cerveau humain, sinon un palimpseste immense et naturel? Mon cerveau est un palimpseste et le vôtre aussi, lecteur. Des couches innombrables d'idées, d'images, de sentiments sont tombées successivement sur votre cerveau, aussi doucement que la lumière. II a semblé que chacune ensevelissait la précédente. Mais aucune en réalité n'a péri. "Toutefois, entre le palimpseste qui porte, superposées I'une sur l'autre, une tragédie grecque, une légende monacale, et une histoire de chevalerie, et le palimpseste divin créé par Dieu, qui est notre incommensurable mémoire, se présente cette différence, que dans le premier il y a comme un chaos fantastique, grotesque, une collision entre des éléments hétérogènes; tandis que dans le second la fatalité du tempérament met forcément une harmonie parmi les éléments les plus disparates. Quelque incohérente que soit une existence, I'unité humaine n'en est pas troublée." (BAUDELAIRE, 2005, p. 97)
} 
ce não ter causado semelhante frisson (para usar a mesma palavra da época), mesmo contendo uma narrativa que poderia ser considerada como certo louvor às drogas abordadas, principalmente o álcool, princípio psicoativo do vinho. $\mathrm{A}$ tolerância com esse texto, que poderia ser facilmente considerado "socialmente danoso" pelos rígidos padrões morais da época, poderia ser explicada pela ausência de conhecimentos científicos sobre os riscos dos ingredientes ativos do haxixe, do ópio e do vinho?

De fato, as principais neurotransmissões cerebrais afetadas pelos princípios ativos dessas drogas, só foram descobertas a partir de meados do século XX. 0 álcool etílico presente no vinho e em outras bebidas alcoólicas estimula a neurotransmissão gabaérgica, a principal no sistema nervoso central e com propriedades inibitórias; o neurotransmissor GABA (ácido gama-aminobutírico) começou a ser descoberto em 1950. Os alcaloides do ópio (morfina, codeína, papaverina etc.) apesar de já serem conhecidos desde o século XIX, quanto às suas propriedades químicas e biológicas, apenas tiveram seu mecanismo de ação central elucidado a partir da década de 1970, com o desvendar do sistema opioide de neurotransmissão cerebral. Já os princípios ativos do haxixe, que têm no tetraidrocanabinol seu principal representante, atuam em um circuito cerebral chamado de sistema endocanabinoide, cujo primeiro receptor foi descoberto apenas em 1990 (BRUNTON et al, 2007; OGA et al., 2014).

Além disso, esses psicoativos podem causar em seus usuários prolongados, dentre tantos outros malefícios, uma doença chamada de farmacodependência ou drogadição, na qual o indivíduo apresenta comportamento compulsivo de busca pela droga, sem a qual já não consegue viver dentro do que se convencionou chamar de normalidade social. Ora, essa propriedade decorre da ação dessas drogas em outro sistema cerebral, conhecido como sistema dopaminérgico mesocorticolímbico, cujo funcionamento e relação com os efeitos de prazer intenso e de dependência química, produzidos por alguns psicoativos, somente começou a ser elucidado a partir da segunda metade do século XX.

Assim, retomamos a pergunta inicial. Teria sido o desconhecimento sobre detalhes dos mecanismos de ação no sistema nervoso central das drogas abordadas em Os paraísos artificiais, uma explicação para a tolerância observada para com esse ensaio pela sociedade da época? Tal desconhecimento teria impedido cientistas e profissionais de saúde a deflagrarem um alerta contra os possíveis 
impactos, na saúde pública, do conselho de Baudelaire: "Deve-se estar embriagado. Nada mais conta" (BAUDELAIRE, 2005)?

$\mathrm{Na}$ busca por respostas (ou, talvez, por mais questionamentos), tentaremos percorrer esse caminho onde arte e ciência, literatura e medicina, transcendência poética e psicofarmacologia, se encontram. Desse modo, nesta análise preliminar, a leitura de um excerto da obra, recortando-se a parte em que discorre sobre o vinho, exemplifica como é possível confrontar a narrativa baudelairiana com os atuais conhecimentos científicos da área a fim de verificar os "teores" de verossimilhança com o que se sabe ser possível observar-se em usuários dessa droga psicoativa.

Sobre um dos principais efeitos do álcool, diz o autor "... um homem que só bebe água tem um segredo a esconder a seus semelhantes..." (BAUDELAIRE, 2005, p. 170). De fato, essa afirmação é atualmente explicada pela psicofarmacologia. O etanol (álcool etílico, presente no vinho e outras bebidas alcoólicas) é uma substância classificada como depressor do sistema nervoso central. 0 detalhe mecanístico é que, inicialmente, quando dos primeiros goles, essa droga vai progressivamente inativando alguns circuitos cerebrais gabaérgicos responsáveis pelo que poderíamos chamar de "freios sociais", o que deixaria o usuário de álcool, em um primeiro momento, aparentemente mais estimulado. Daí, portanto, quando alguém bebe, inicia com sorrisos abertos, risadas, gargalhadas, até se apresentar com total desinibição, em plena perda de mecanismos de autocontrole, tornando-se portanto, vulnerável a revelar segredos e comportamentos até então, guardados debaixo de sete chaves.

Fica claro que, em meados do século XIX, mesmo sem as atuais ferramentas da biologia molecular para desvendar os mistérios cerebrais, pôde-se utilizar outras estratégias para conhecer os efeitos das drogas; entre elas: a experimentação, a observação de outros usuários e mesmo os protocolos científicos menos elaborados. Esses meios permitiram um conhecimento relativamente adequado sobre, inclusive, alguns dos surpreendentes efeitos de drogas psicoativas, como por exemplo, essa aparente contradição da estimulação inicial produzida por uma bebida alcoólica.

Continuando a reflexão sobre o porquê de a obra não ter sido repudiada socialmente como outras do mesmo autor, poderíamos apresentar como uma primeira possível explicação, para o caso do álcool, o fato de ser uma droga lícita e não apenas socialmente aceita quanto até promovida, tendo chegado ao status 
de ou representante do sangue de Cristo ou o próprio sangue, de acordo com alguns segmentos da comunidade cristã ocidental. Ademais, podemos pensar que a mimese da descrição dos efeitos do álcool gera, na maior parte dos leitores, identificação com o traço realístico do ensaio, nesse e em outros aspectos, fazendo o leitor (individualmente e como sociedade) render-se aos fatos e à verdade apresentada pelo poeta ensaísta.

Outra possível explicação para tal façanha, talvez seja a força poética da narrativa que, ao colocar vinho, poesia e virtude, em um mesmo patamar de capacidade produtora de transcendência inebriante, dilui o foco do vinho, quando da sugestão feita de "embriagar-se" como fuga dos sofrimentos da vida, e leva a atenção do leitor para o fato de que o vinho (e outros psicoativos, talvez) são apenas opções de bálsamos para alívio das dores de quem sofre. Ou seja, existem alternativas mais saudáveis e moralmente nobres, tais como a poesia e a virtude.

...deve-se estar embriagado. Nada mais conta. Para não sentir o horrível fardo do Tempo que esmaga os vossos ombros e vos faz pender para a terra, deveis embriagar-vos sem tréguas.

Mas de quê? De vinho, de poesia ou de virtude, à vossa escolha. Mas embriagaivos. (BAUDELAIRE, 2015, p. 189)3.

Outro aspecto das ciências da saúde que pode ressaltar o ar vanguardista da obra é o fato de que, recentes trabalhos sobre o desenvolvimento de estratégias de prevenção ao uso indevido de drogas, em diversos segmentos populacionais e sociais, principalmente entre adolescentes e na Escola de Ensino Fundamental e Médio, destacam que é importante oferecer formas alternativas de obtenção de prazer. Entendemos, desse modo, que talvez, um dia o mundo aprenda a "embriagar-se de poesia ou de virtude", pois por enquanto, segue-se optando pelos "vinhos da vida", talvez porque a nossa poesia ou virtude ainda nos sejam menos "inebriantes".

3 Il faut être toujours ivre. Tout est là: c'est l'unique question. Pour ne pas sentir l'horrible fardeau du Temps qui brise vos épaules et vous penche vers la terre, il faut vous enivrer sans trêve.

Mais de quoi ? De vin, de poésie ou de vertu, à votre guise. Mais enivrez-vous. (BAUDELAIRE, 2001, p. 28). 
Deve-se considerar, ainda, que o respeito ao livre arbítrio da sugestão baudelairiana, "à vossa escolha", talvez também tenha diluído possíveis julgamentos moralistas e prevenido reações efusivas à obra em questão. Essa postura de respeito às liberdades individuais corrobora o que existe de mais atual em termos de perspectiva de abordagem de um dos grandes problemas de saúde pública dos nossos dias: o uso indevido de drogas (sobretudo as lícitas) e a farmacodependência. Trata-se da perspectiva de redução de danos, na qual, abandonando-se a política pública de priorização da repressão investe-se majoritariamente na minimização dos danos individuais e coletivos do envolvimento com drogas psicoativas. Parte-se da percepção de que, dentro dos direitos individuais, usar alguma droga sem prejudicar a outros, seria uma opção do indivíduo. A preocupação é maior com o uso indevido de drogas lícitas, e, dentre as ilícitas, maior atenção é dada às injetáveis pelos riscos de comorbidades resultantes da transmissão de doenças como a AIDS. (DIEHL; FIGLIE, 2014; RONZANI et al., 2015).

Em outro momento do texto sobre o vinho, o poeta fecha seus comentários com um tom de menor apologia a essa droga, exaltando traços de personalidade como "entusiasmo e vontade" enquanto promotores mais nobres de enlevo espiritual e inspiração para criação poética.

Termino este artigo com algumas belas palavras que não são minhas, mas de um notável filósofo pouco conhecido, Barbereau, teórico musical e professor do Conservatório. Estava junto dele numa reunião em que algumas pessoas tinham tomado o veneno bem-aventurado, e ele disse com uma expressão de desprezo indizível: "Não compreendo porque o homem racional e espiritual se serve de meios artificiais para chegar à beatitude poética, uma vez que o entusiasmo e a vontade bastam para elevá-lo a uma existência supranatural. Os grandes poetas, filósofos, os profetas são seres que pelo puro e livre exercício da vontade chegam a um estado em que são ao mesmo tempo causa e efeito, sujeito e objeto, magnetizador e sonâmbulo".

Penso exatamente como ele. (BAUDELAIRE, 2005, p. 188) ${ }^{4}$.

\footnotetext{
4 Je termine cet article par quelques belles paroles qui ne sont pas de moi, mais d'un remarquable philosophe peu connu, Barbereau, théoricien musical, et professeur au Conservatoire. J'étais auprès de lui dans une société dont quelques personnes avaient pris du bienheureux poison, et il me dit avec un accent de mépris indicible: "Je ne comprends pas pourquoi l'homme rationnel et spirituel se sert de moyens artificiels pour arriver à la béatitude poétique, puisque l'enthousiasme et la
} 
Desse modo, para o leitor que chega ao final de Os paraísos artificiais, não há como nutrir alguma aversão ou repulsa moral que porventura the tenha brotado ao longo do texto. Próximo ao final do seu discurso sobre o vinho, o poeta ensaísta reconhece que muito ainda existia a se conhecer sobre a capacidade do vinho (e seu psicoativo, o álcool) de conduzir o ser humano por labirintos mentais, de certo modo, ainda desconhecidos. Por esse viés, ele sinaliza para a importância de estudos interdisciplinares, como o que tentamos esboçar com esse texto.

Nada vos ensinei de novo. O vinho é conhecido de todos; é amado de todos. Quando houver um verdadeiro médico filósofo, coisa que não se vê, poderá fazer um importante estudo sobre o vinho, uma espécie de psicologia dupla, cujos dois termos são o vinho e o homem. Explicará como e por que certas bebidas contêm a faculdade de aumentar desmedidamente a personalidade do ser pensante..., e de criar, por assim dizer, uma terceira pessoa, operação mística, em que o homem natural e o vinho, o deus animal e o deus vegetal, desempenham o papel do Pai e do Filho na Trindade; engendram um Espírito Santo, que é o homem superior, o qual procede igualmente os dois." (BAUDELAIRE, 2015, p. 175)

Nesse discurso final do ensaio sobre as três drogas, o vinho parece ser a chave que explicaria o porquê de a tradicional sociedade francesa não ter reagido com tanta veemência contra Os paraísos artificiais, além disso, evidentemente, o poeta não afronta de maneira nenhuma a boa sociedade, como parece ter sido em As flores do mal, com poemas que claramente cultuavam a prostituta, por exemplo, como em Une charogne [Uma carniça] ou La muse vénale [A musa venal]. Não obstante, se perceba a presença de certa ode ao vinho enquanto

volonté suffisent pour l'élever à une existence supra-naturelle. Les grands poètes, les philosophes, les prophètes sont des êtres qui par le pur et libre exercice de la volonté parviennent à un état où ils sont à la fois cause et effet, sujet et objet, magnétiseur et somnambule." Je pense exactement comme lui. (Baudelaire, 2001, p.: 29).

5 Je ne vous ai rien appris sans doute de bien nouveau. Le vin est connu de tous; il est aimé de tous. Quand il y aura un vrai médecin philosophe, chose qui ne se voit guère, il pourra faire une puissante étude sur le vin, une sorte de psychologie double dont le vin et l'homme composent les deux termes. Il expliquera comment et pourquoi certaines boissons contiennent la faculté d'augmenter outre mesure la personnalité de l'être pensant, et de créer, pour ainsi dire, une troisième personne, opération mystique, où l'homme naturel et le vin, le dieu animal et le dieu végétal, jouent le rôle du Père et du Fils dans la Trinité; ils engendrent un Saint-Esprit, qui est l'homme supérieur, lequel procède également des deux. (BAUDELAIRE, 2001, p. 14). 
instrumento de celebração, essas palavras somadas às do filósofo Barbereau nos fazem entender a obra como um não louvor à dependência química. Isso se explica também pelo viés simbolista da obra baudelairiana, de inspiração no sueco espiritualista Emanuel Swedenborg (1688-1772), para quem, a realidade apenas reverbera o divino; as ligações entre as coisas do mundo visível fundem-se com o invisível, o místico. Baudelaire utiliza apenas da estética desse prisma a fim de, em Correspondências, dar vazão às sinestesias potencializadas, por exemplo, pelo haxixe, sem implicações ao espírito, pois o foco dessa obra é uma percepção sensorial diferenciada do real.

Assim, pelas trilhas do espiritualismo, o poeta deixa transparecer o seu pensamento de fonte swedenborguiana, com sua formação polímata que parece ter deixado em Baudelaire uma forte presença, uma vez que, além de ícone da poesia, foi crítico de arte e grande ensaísta, como se pode perceber em Os paraísos artificiais.

\section{Considerações Finais}

As diversas sociedades têm sido, ao longo de suas respectivas trajetórias, fortemente influenciadas pelo mundo das artes, sobretudo da literatura. No ocidente, merece destaque a produção francesa do século XIX com proeminência para os poetas malditos, em especial, Charles Baudelaire. Nesse autor, observa-se uma produção atualizada, viva e tão fecunda que passeia, tranquilamente, por diversos domínios do conhecimento, reforçando a sua constituição polímata, saindo das artes literárias e indo, por exemplo, para as ciências da saúde, como se vê na jovem ciência conhecida como psicofarmacologia, que se ocupa em estudar as substâncias com ações e efeitos na psique humana.

Mas, como Baudelaire, em Os paraísos artificiais teria conseguido escapar da repulsa social angariada com outras obras, ao descrever, com uma certa apologia, em dados momentos da narrativa, os efeitos dos prazeres transcendentes produzidos por ópio, haxixe e vinho, com um espantoso grau de verossimilhança, mesmo sem existirem conhecimentos científicos aprofundados em sua época sobre as neurotransmissões cerebrais e a interferências dos princípios psicoativos das drogas em tais mecanismos? 
Na busca por possíveis respostas ou tentativas de explicações para essa indagação, enveredamos, nesse texto, por uma leitura preliminar, principalmente de alguns excertos da parte em que o autor discorre sobre o vinho, a fim de, com o olhar da psicofarmacologia moderna, observar a narrativa mimética e constatar que o poeta lançou mão não apenas da estratégia de fazer o leitor se identificar com a obra, mediante uma descrição realística das sensações produzidas pelo vinho, como também pela mestria da sua escrita, que nos instiga a refletir sobre quais (e o quão saudáveis) são Os paraísos artificiais dos quais lançamos mão frequentemente para suportar nossos sofrimentos cotidianos.

Por certo, Os paraísos artificiais constituem-se em um marco tanto para a literatura, quanto para a medicina por ser um ensaio literário com grande força poética, mas também tratar-se de uma obra que instiga o leitor a perguntar-se constantemente: como pôde, o poeta, narrar fatos tão claros e que só puderam ser explicados mais tarde, à luz dos conhecimentos atuais? O visionário Baudelaire é, certamente, um dos maiores nomes da literatura universal e, nesse ensaio, deixa sua presença marcante como aquele que ele mesmo chamou de "verdadeiro médico filósofo", o que, na segunda metade do século XIX, era "coisa que não se vê". Nele, reconhecemos esse "médico filósofo". Ao longo dos anos, ele parece ter provado ser coisa que se vê e que ficou registrado na história da literatura. 


\section{Referências}

AMARAL, Glória Carneiro do. Aclimatando Baudelaire. São Paulo: Annablume, 1996.

BARTHES, Roland. Le plaisir du texte. Paris: Points Essais, 2014.

BAUDELAIRE, Charles. Os paraísos artificiais. Trad. José Saramago. Rio de Janeiro: Ediouro, 2005.

BAUDELAIRE, Charles. Du vin et du haschisch. Essais Classiques. Paris: Ed. Mille et une nuits. 2001.

BAUDELAIRE, Charles. Le spleen de Paris: petits poèmes en prose. Paris: Flammarion. 1997.

BENJAMIN, Walter. Baudelaire e a modernidade. Trad. João Barrento. Belo Horizonte: Autêntica. 2015.

BRUNTON, Laurence L.; LAZO, Jonh S.; PARKER, Keith L. Goodman \& Gilman, as bases farmacológicas da terapêutica. Rio de Janeiro: McGraw-Hill, 2007.

DIEHL, Alessandra; FIGLIE, Neliana Buzi. Prevenção ao uso de álcool e drogas - o que cada um de nós pode e deve fazer? Porto Alegre: Artmed, 2014.

OGA, Seizi; CAMARGO, Márcia Maria de A.; BATISTUZZO, José Antônio de O. Fundamentos de toxicologia. São Paulo: Atheneu Editora, 2014.

RONZANI, Telma Mota; COSTA, Pedro Henrique Antunes da; MOTA, Daniela Cristina Belchior; LAPORT, Tamires Jordão. Redes de atenção aos usuários de drogas: políticas e práticas. São Paulo: Cortez Editora, 2015.

Submetido em: 30-11-2015 Aprovado para publicação: 17-05-2016 